\title{
EL PROBLEMA DE LA VIVIENDA EN EL PUERTO DE LA CRUZ 1900-1980: LAS CIUDADELAS COMO SOLUCIÓN HABITACIONAL DE EMERGENCIA
}

\author{
Nicolás D. Barroso Hernández*
}

\section{RESUMEN}

Este artículo analiza la situación de la vivienda en el Puerto de la Cruz en el período de 1900-1980, así como las políticas implementadas por la administración municipal para dar cobertura a esta necesidad social básica, centrándolo, de forma específica, en el fenómeno habitacional de las ciudadelas. Se identifican dos etapas: prefranquista, donde la promoción de «ciudadelas» queda en manos del sector privado, y franquista, período en que el sector público municipal se convierte en el promotor -casi exclusivo- de las «viviendas colectivas obreras». En todo caso, no se trata de agotar la cuestión, sino de ofrecer un esquema informado de su presencia y encuadre de las «ciudadelas» en las políticas municipales de vivienda aplicadas, incorporando -cuando la documentación disponible lo permita- un inventario y descripción cualitativa y cuantitativa de cada una de ellas.

Palabras clave: ciudadelas, vivienda colectiva obrera, política municipal de vivienda, Puerto de la Cruz.

\section{THE PROBLEM OF HOUSING IN PUERTO DE LA CRUZ 1900-1980: WORKING CLASS TENEMENT HALLS AS AN EMERGENCY HOUSING SOLUTION}

\section{Abstract}

This article analyzes the situation of housing in Puerto de la Cruz, in the period between 1900-1980, as well as the policies implemented by the local administration to cover this basic social need, focusing it, more specifically, on the housing phenomenon of the "ciudadelas» (working class tenement halls/housing). Two periods are identified: the pre-Franco dictatorship, where the promotion of "ciudadelas» is in the hands of the private sector; and the Franco dictatorship, period in which the municipal public sector becomes the promoter -almost exclusively- of the "working class tenement halls/housing». In any case, it is not a matter of exhausting the subject, but rather of offering a detailed outline of their presence and accurate framing of the "ciudadelas" in the municipal housing policies applied, incorporating -when the available documentation allows- an inventory and qualitative and quantitative description of each of them.

KEYwords: citizens, workers' collective housing, municipal housing policy, Puerto de la Cruz. 
La vivienda es una necesidad social básica que vertebra la política urbanística del Ayuntamiento del Puerto de la Cruz a lo largo del siglo pasado, realizando un esfuerzo sostenido en la provisión de una oferta de suelo residencial y de vivienda; bien a través de la aplicación de medidas específicamente municipales (1900-1936), bien promoviendo urbanizaciones y grupos de vivienda protegida sustentados en planes y financiación de administraciones supramunicipales (1950-1981). A pesar de ello, su oferta ha sido y es estructuralmente deficitaria, y ha ido siempre por detrás de las necesidades de cada momento, tanto la vivienda social de promoción pública como la destinada al mercado libre.

La ciudadela es un modelo de vivienda obrera que se repite en toda la geografía española durante la segunda mitad del siglo xIx y primera mitad del xx, y que en cada ciudad, provincia o región, recibe diferentes denominaciones: «Patios, corrales de vecinos, ciudadelas, casas de corredor, corralillos, portones, barrios ocultos, etc. son denominaciones en buena medida sinónimas para modelos de alojamientos de masas que guardan gran parentesco entre sí. Por razones que son más que formales se pueden distinguir dos tipos, los corrales con corredor y los patios o ciudadelas» ${ }^{1}$. El profesor Ramón Pérez, en «Las Ciudadelas de Santa Cruz de Tenerife», proporciona la siguiente definición: «La Ciudadela es un tipo de vivienda colectiva, desarrollada por lo general en planta baja, constituida por un cierto número de habitaciones independientes entre sí, dispuestas a ambos lados de un callejón ciego de anchura y longitud variable según los casos, o en torno a un patio, que tienen en común un único acceso desde la calle, con frecuencia velado, y casi siempre también los retretes y la cocina $»^{2}$.

Si bien es un edificio de titularidad privada en régimen de alquiler, de lo que Santa Cruz es un excelente ejemplo, en el Puerto de la Cruz, con la llegada del régimen franquista se modifica esta situación, y una parte importante de las viviendas colectivas obreras tendrán carácter público municipal, ubicadas en edificios públicos o privados -gestionados por el Ayuntamiento-. Por ello, hemos englobado esta solución habitacional dentro de las políticas públicas de vivienda, tanto en este artículo como en nuestra tesis doctoral ${ }^{3}$. En el desarrollo expositivo de este artículo, la política municipal de vivienda ha servido de introducción al análisis del origen, forma, titularidad y pervivencia del modelo residencial de las ciudadelas a lo largo de la primera mitad del siglo $\mathrm{xx}$.

* Doctor en Geografía. Área Municipal de Bienestar Social. Ayuntamiento del Puerto de la Cruz.E-mail: nicba@telefonica.net.

1 Gómez Mendoza, Josefina, «Nuestro Quirós» (Universidad Autónoma de Madrid-Real Academia de la Historia), en Quirós Linares, Francisco, Estudios de Geografía Histórica e Historia de la Geografía -Obra Escogida-, Servicio de Publicaciones de la Universidad de Oviedo, Asturias, 2005. p. 19.

2 Pérez González, Ramón, Las ciudadelas de Santa Cruz de Tenerife, Enciclopedia Canaria, Aula de Cultura de Tenerife, 1982. p. 5.

${ }^{3}$ Barroso Hernandez, Nicolás D., Puerto de la Cruz: Desarrollo Urbano y Organización del Espacio en el siglo XX (tesis doctoral inédita), Universidad de La Laguna, febrero de 2016. 
En este amplio período de tiempo, se identifican dos etapas:

a) Etapa prefranquista: entre 1900 y 1936, en que surgen las primeras viviendas colectivas obreras "ciudadela» en el Puerto de la Cruz. Coincide con la creación en 1903 del Instituto de Reforma Social y, más concretamente, la primera Ley de Casas Baratas de 1911 y las medidas legales que la siguieron, cuyos efectos son perceptibles en el municipio; así como la aplicación que de estas y otras medidas hicieron la dictadura de Primo de Rivera y la II República.

b) Etapa franquista: comprende la mayor parte del régimen dictatorial surgido del golpe de Estado de Francisco Franco en 1936, hasta 1978. Es el momento de creación del Instituto Nacional de la Vivienda, Obra Sindical del Hogar, etc., que desarrollan una intensa actividad en la construcción de vivienda pública. En el ámbito específicamente municipal, incluye la aprobación del PGOU de 1958 e incluso los primeros pasos del PGOU de 1974 y las adaptaciones de 1978 y 1979, que marcan las líneas generales de la política municipal de vivienda.

\section{A) Etapa PREFranquista}

El Puerto de la Cruz, durante el primer tercio de la centuria, mantiene su condición de centro portuario de segundo orden -el tercero del Archipiélago por el volumen de tráfico-, con una actividad económica centrada en el sector primario, dominado por el cultivo platanero -en plena expansión- y la actividad pesquera tradicional. Este marco básico se completa con un sector servicios importante, vinculado al comercio y un emergente subsector turístico. Es un período política y económicamente convulso, en el que se suceden situaciones de conflicto y de crisis, como la I Guerra Mundial (1914-1918), la Guerra de Marruecos o del Rif (1911-1926) y la Gran Depresión (crack de la Bolsa de Nueva York de 1929). En clave interna, es un período de importantes cambios en el sistema político de gobierno, que transita por la monarquía parlamentaria, la dictadura de Primo de Rivera y la II República, para culminar con el golpe de Estado de 18 de julio de 1936 y la Guerra Civil.

Un período caracterizado por un balance demográfico de signo positivo, especialmente intenso en los decenios 1920-30 y 1930-40, en que continúa abierto el proceso de ruralización iniciado a partir de 1820 , consistente en el progresivo retroceso de la economía urbana vinculada a la actividad portuaria y comercial, unido a la transformación del Puerto de la Cruz en un municipio eminentemente agrícola, circunstancia que en el ámbito sociodemográfico se concreta en la pérdida de importancia relativa de la población del centro urbano y el incremento de la población de los barrios de la periferia rural (cuadro I).

La política de vivienda del Ayuntamiento centró sus esfuerzos en la implementación de medidas destinadas a resolver el elevado déficit de vivienda de la población trabajadora. En general, la dinámica social concentra la localización de 


\begin{tabular}{lccccc}
\hline \multicolumn{5}{c}{ CUADRO I. EVOLUCIÓN DE LA POBLACIÓN DURANTE EL PERÍODO 1900-1940, } \\
POR ZONAS GEOGRÁFICAS
\end{tabular}

Fuente: INE: censos de población de 1900, 1910, 1920, 1930, y 1940. Elaboración propia.

estas iniciativas en torno a los centros de la actividad económica emergente, en este momento el cultivo platanero, y en menor medida el tráfico portuario, comercio, turismo y pesca; de este modo, los obreros agrícolas orientan su demanda a los caseríos de la periferia agrícola; mientras que la mano de obra vinculada a la actividad portuaria, pesquera y de servicios buscará alojamiento en el centro urbano. Las iniciativas políticas del Consistorio en esta materia son abundantes, especialmente durante la dictadura de Primo de Rivera y en la II República. En términos generales, las medidas aplicadas en materia de vivienda son:

- Reparto de solares: consistente en la parcelación y distribución de solares en suelo público para la autoconstrucción de viviendas. Estas iniciativas son las más eficaces y se concentran especialmente en los decenios 1900-1910, 1920-1930 y 1930-1936. Localizados en los barrios agrícolas de San Antonio-Esquilón, Calle Nueva-Las Arenas y las zonas urbanas de Punta Brava (a partir de 1926) y casco urbano (fecha 1934) (cuadro II).

\begin{tabular}{lccccc}
\hline \multicolumn{5}{c}{ CUADRO II. NÚMERO DE EDIFICIOS DE VIVIENDAS EN EL PERÍODO } & $1900-1940$, \\
POR ZONAS GEOGRÁFICAS & 1920 & 1930 & 1940 \\
\hline VIVIENDAS & 1900 & 1910 & 685 & 746 & 809 \\
\hline Centro urbano & 654 & 654 & 586 & 743 & 883 \\
\hline Periferia rural & 387 & 530 & $\mathbf{1 2 7 1}$ & $\mathbf{1 4 8 9}$ & $\mathbf{1 6 9 2}$ \\
\hline TOTAL & $\mathbf{1 0 4 1}$ & $\mathbf{1 1 8 4}$ & & 1930 & 1940 \\
\hline Viviendas & 1900 & 1910 & 1920 & $50,10 \%$ & $47,81 \%$ \\
\hline Centro urbano & $62,82 \%$ & $55,24 \%$ & $53,89 \%$ & $49,90 \%$ & $52,19 \%$ \\
\hline Periferia rural & $37,18 \%$ & $44,76 \%$ & $46,11 \%$ & 1909 \\
\hline
\end{tabular}

Fuente: Instituto Nacional de Estadística. Nomenclátores de 1900, 1910, 1920, 1930 y 1940. Elaboración propia. 


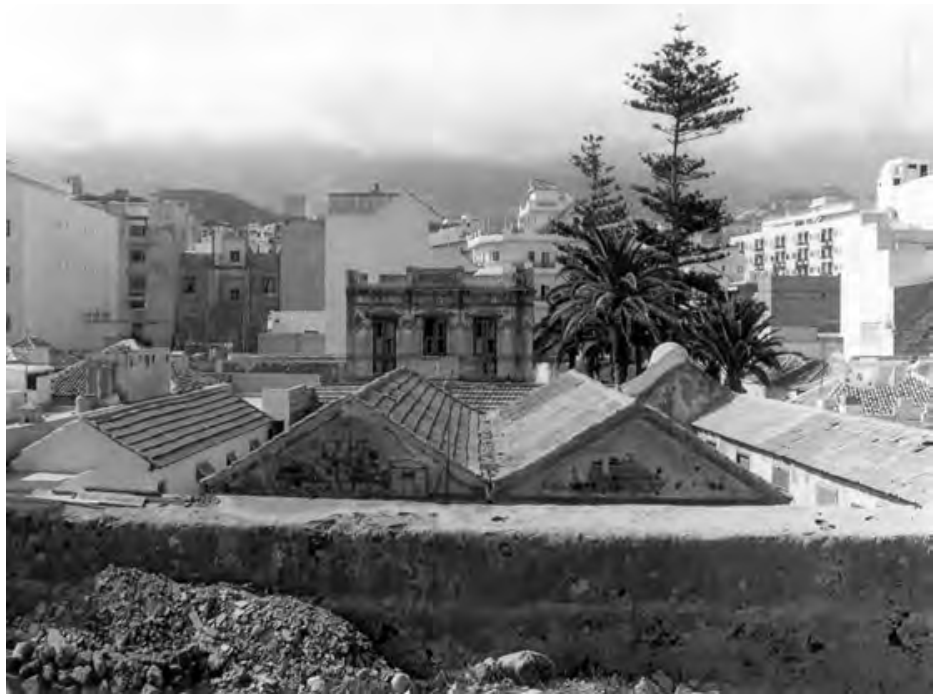

Foto 1. Ciudadela de Mequinez o Adelaida. En primer plano, el muro de protección frente a las crecidas del mar. Cuatro naves -la nave central es doble-, separadas por dos pasillos.

- Casas baratas: en principio constan varios proyectos que promueven viviendas de este tipo, si bien no se ha podido determinar su alcance y eficacia, en la medida en que la documentación no ha permitido verificar su efectiva ejecución.

- Ciudadelas: surgen en este período como solución al grave problema de alojamiento de la población trabajadora más humilde en el medio urbano. Tenemos registro de tres; dos de carácter privado, que coexisten con un edificio que sirve de alojamiento obrero colectivo, de gestión pública.

En el Puerto de la Cruz existieron tres ciudadelas: a) La Ciudadela de Mequinez o «Adelaida», b) Los Cubanos y c) convento de San Francisco:

a. «La Ciudadela» de Mequinez (Adelaida) (foto 1): es el resultado del «reaprovechamiento» o adaptación de un edificio concebido y construido para un uso distinto al de vivienda colectiva ${ }^{4}$. Se ubica en la fachada norte de la calle

${ }^{4}$ TATJer, M., «La vivienda obrera en España de los siglos Xix y xx: de la promoción privada a la promoción pública (1853-1975)». Scripta Nova. Revista electrónica de geografía y ciencias sociales. Barcelona: Universidad de Barcelona, 1 de agosto de 2005, vol. Ix, núm. 194 (23). <http://www. ub.es/geocrit/sn/sn-194-23.htm> [ISSN: 1138-9788]. p. 12: «El reaprovechamiento y compartimentación de edificios y también de antiguas fábricas, así como las construcciones en patios interiores o en los terrados de los inmuebles para crear pequeñas viviendas para obreros fue también una cons- 
Mequinez, de espaldas al mar; en un inmueble que, como el resto de edificios de la calle, está sometido a un elevado riesgo de sufrir daños por la acción del mar, por lo que en su parte trasera cuenta con un muro de protección que se prolonga a lo largo de la vía. La información referente a la misma la hemos obtenido gracias a la colaboración de doña Rafaela Concepción de Cabo Martín, nacida en 1927 en La Ciudadela. Era un inmueble de titularidad privada y se abona una renta mensual en concepto de alquiler a sus propietarios. El edificio estaba formado por naves dispuestas longitudinalmente, en sentido norte-sur. Estas estaban separadas por dos pasillos, en torno a los que se disponen ocho viviendas, separadas en dos grupos de cuatro cada una, conformando un conjunto de 16 viviendas en total. Disponían de un retrete común para cada nave de ocho viviendas. Cada habitáculo tenía dos cuartos o habitaciones, aunque el de nuestra informante era una excepción, pues tenía tres piezas. La superficie era extremadamente reducida, y algunas familias eran muy numerosas; concretamente doña Concha tuvo nueve hijos y no disponían de agua corriente, solo de un estanque o pileta para lavar la ropa, que compartían todos los moradores. Tampoco dispusieron de suministro de energía eléctrica hasta bien avanzado el siglo xx (1962). Su familia, en todo caso, dispuso antes de este servicio porque su esposo estuvo enfermo y la necesitó.

La mayor parte de los vecinos eran pescadores, y algunas de las mujeres - para completar los ingresos familiares-iban a vender el pescado a las zonas altas del valle de La Orotava. Los problemas higiénicos eran muy graves, de modo que vivían en medio de una constante plaga de piojos, además de otros insectos y enfermedades. Otro informante más joven ha referido los problemas que tenían para mantener una higiene personal mínima, por lo que en su edad infantojuvenil iba a asearse al "chorro del muelle pesquero". A ello se unen los problemas ocasionados por las colas para lavar la ropa y los calderos, así como para el uso del retrete. Se trata de un grupo de familias trabajadoras, cuya renta salarial no es suficiente para acceder a una vivienda unifamiliar, viéndose impelidas a recurrir a este tipo de solución habitacional colectiva.

b. Ciudadela del edificio Los Cubanos (calle de Mequinez-plaza Pérez Galdós): el propietario es don Dionisio Martín Yumar, el cual en 1928 solicita licencia municipal para «reformar la casa n. ${ }^{\circ} 45$ de la calle Mequinez esquina a la plaza Pérez Galdós» ${ }^{5}$, con el objeto de añadir una segunda planta a la vivienda. En la solicitud de licencia de obra no se hace referencia alguna a la vecina ciudadela, aunque fuentes orales señalan que esta vivienda

tante de las grandes ciudades españolas, entre las que destaca Barcelona. El resultado fue la densificación y la insalubridad de muchas viviendas proletarias del centro de las ciudades, situación ampliamente denunciada por los higienistas a lo largo de los siglos XIX y XX».

5 AMPC, Obras Públicas y Urbanismo, Instancia y Plano presentado por don Dionisio Martín Yumar, Legajo 134. 1928. 
familiar forma parte de una gran parcela urbana, cuya prolongación meridional y oriental está destinada a "ciudadela», con fachada a la plaza Pérez Galdós y salida a la calle Mequinez. El testimonio oral de una informante que residió hasta los 17 ańos señala que de acuerdo con referencias de su abuela, la ciudadela Los Cubanos está en funcionamiento desde comienzos del siglo $\mathrm{xx}^{6}$. La información referente a la vivienda colectiva ha sido obtenida a través de don Manuel Carballo López, nacido en 1917, y que pasó a residir en esta ciudadela cuando contrajo matrimonio. La ciudadela Los Cubanos no es un edificio adaptado o reconvertido en vivienda colectiva, sino una parcela o patio trasero de una vivienda familiar, en la que se construyen unos habitáculos para familias de obreros con baja remuneración; en todo caso, en la documentación consultada en el archivo municipal, no consta solicitud o licencia de obra emitida para la ejecución de las mismas. La ciudadela está formada por siete viviendas, con un solo cuarto que el mismo don Manuel se encargó de compartimentar en dos habitaciones. La cubierta era de uralita y tenía cocina individual aparte, con techo de cemento; motivo por el cual servía como lugar de refugio, cuando había tormenta. Disponían de un retrete para cada tres familias. Además, contaban con dos estanques o piletas para todos los inquilinos. No disponía de agua corriente individual, ni de luz eléctrica; al menos, en la primera mitad del siglo. Se trata de una vivienda colectiva privada, en la que se abona una renta mensual. Las condiciones higiénicas y sanitarias, según don Manuel, eran similares a Mequinez.

Las ciudadelas de Mequinez y Los Cubanos se localizan en el barrio de La Ranilla, en el extremo septentrional del casco urbano, un área sometida a un riesgo potencial elevado de ser afectada por las crecidas del mar, especialmente la de Mequinez ${ }^{7}$; la construcción de la escollera del Parque Marítimo en la década de los años ochenta no ha sido suficiente para para eliminar el riesgo ${ }^{8}$. En todo caso, históricamente ha sido un espacio que ha albergado a sectores de población trabajadora con bajo nivel de renta, cumpliendo, por tanto, la condición de localización periférica común al modelo habitacional de la ciudadela.

${ }^{6}$ Considerando referencias de su abuela, que vivió en Los Cubanos desde que contrajo matrimonio y a partir de la edad de los hijos de esta, entiende que la misma entró en funcionamiento mucho antes de 1928.

7 Una informante de la ciudadela de Mequinez refirió que dońa Concha alertaba a todos los moradores de las inminentes crecidas del mar, golpeando una bañera de cinc u otros utensilios metálicos para ponerse a salvo. Dońa Concha era alertada, según nuestra informante, por su esposo, que era pescador y era capaz de anticipar las crecidas del mar.

${ }^{8}$ Barroso Hernandez, Nicolás D., Puerto de la Cruz: Desarrollo Urbano y Organización del Espacio en el siglo XX (tesis doctoral inédita), Universidad de La Laguna, febrero de 2016, pp. 52 y 53. Los mapas de Peligrosidad y Riesgo de Inundación de las ARPSIPs en la Demarcación Hidrográfica de Tenerife de octubre de 2014 mantienen esta zona dentro del área de riesgo. 


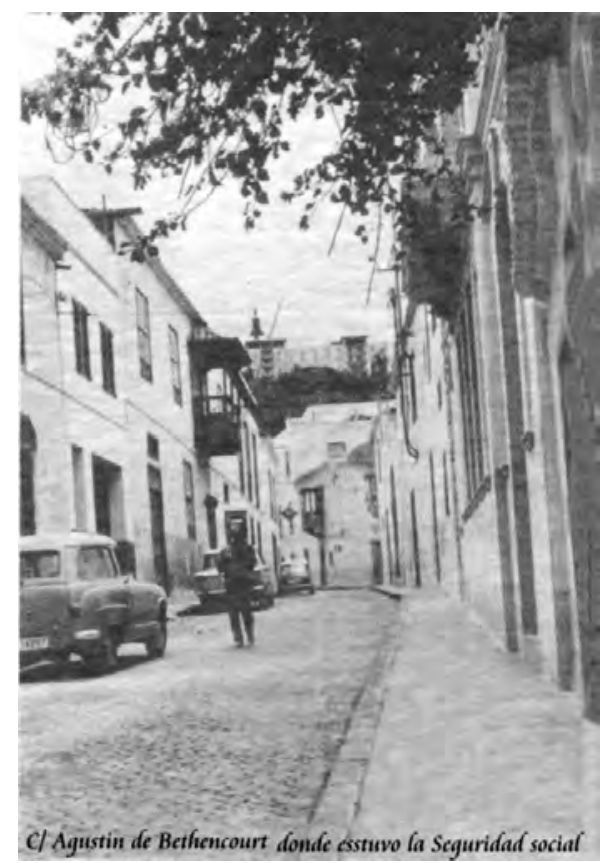

Foto 2. Ciudadela del "convento de San Francisco». Fachada a la calle Agustín de Bethencourt, destinada a viviendas de empleados públicos.

c. Convento de San Francisco (foto 2): el antiguo convento de San Francisco, tras la desamortización, había pasado a ser de titularidad privada y estaba arrendado por el Ayuntamiento. En 1912, el concejal don Pedro Cruzat denuncia las malas condiciones en que se halla el edificio, refiriéndose al mismo como «Depósito Municipal». La Alcaldía, a través de una providencia, encomienda la elaboración de un informe al comisario don Pedro Corrales Casado, fechado el 8 de octubre de 1912, cuya lectura da a conocer el uso real del inmueble que subyace tras el eufemismo de «Depósito Municipal». El encabezado del informe es el siguiente: «En virtud de habérseme presentado los guardias municipales manifestando que el edificio destinado a casa cuartel de los mismos, propiedad del Municipio y sito en la calle de Don Agustín de Bethencourt, se encuentra en malas condiciones de higiene, me presenté en dicho edificio»". A partir de este punto, el informe describe una vivien-

9 AMPC, Beneficencia, Sanidad y Calamidades Pública, legajo 60, expediente n. ${ }^{\circ} 14$ (19111912). Expediente instruido, en vista de denuncia formulada sobre malas condiciones higiénicas y de salubridad que reúne la casa de «Depósito Municipal», situada en la calle de "Agustín de Bethencourt» (1911-1912). 
da colectiva perfectamente asimilable a una "ciudadela", en la que residen ocho familias y, aproximadamente, 20 personas que comparten dos aseos o retretes y un lavadero, todo ello en pésimas condiciones de uso y salubridad. Los residentes son cinco familias de empleados públicos (tres guardias, el portero y el guardián municipales), una mujer «incapacitada», una familia formada por padre y tres hijos y un bodeguero con esposa y cuatro o cinco hijos $^{10}$. Se trata de un edificio de "uso público», adscrito a un uso residencial colectivo, al que la masificación, falta de mantenimiento y uso compartido de pila y retretes confieren la condición de «ciudadela».

En resumen, durante el primer tercio del siglo xx en el Puerto de la Cruz, además de políticas de «reparto de solares» y de inciertos programas de "casas baratas» localizadas preferentemente en la periferia agrícola o donde hay suelo público disponible, el importante crecimiento demográfico genera modelos de vivienda colectiva para población trabajadora urbana. Este momento está dominado por una oferta de vivienda obrera colectiva privada en régimen de alquiler, aunque no en edificios construidos específicamente para ese fin, sino adaptados por sus propietarios para darles un uso alojativo: ciudadelas de Mequinez y Los Cubanos; cumplen además, la condición geográfica de localización periférica en zona sometida al riesgo de inundaciones del mar.

Dentro del casco urbano, se encuentra el convento de San Francisco, destinado a «Depósito Municipal», combinado con residencia colectiva de familias de empleados municipales, y otros perfiles sociales, que conviven en unas condiciones higiénicas y sanitarias asimilables a la tipología habitacional de las ciudadelas. La novedad, en este caso, es que se trata de un edificio de «uso público» y no consta que haya de abonarse renta alguna al Ayuntamiento. Otro aspecto relevante es que se localiza en el centro del casco urbano.

\section{B) Etapa franquista}

Durante el régimen político surgido del golpe de Estado de 1936, se mantienen en funcionamiento las tres ciudadelas señaladas, a las que se suman nuevas iniciativas de vivienda obrera colectiva, que incorporan elementos innovadores en su génesis, forma y localización. Nuestro análisis aborda el período de treinta y nueve años que va desde la conclusión de la Guerra Civil, hasta 1978, en plena transición a la democracia, tras la muerte del dictador. En este período «la Dictadura franquista interviene de forma intensa y fuertemente regulada en materia de vivienda... La acción del Estado se dejó sentir a través de un entramado de diferentes organismos en el marco del nacionalsindicalismo (Instituto Nacional de la Vivienda, Obra 
Sindical del Hogar, Gobiernos civiles, Patronato Francisco Franco, etc.) así como por la actuación de los propios municipios e incluso de las Diputaciones» ${ }^{11}$.

Se caracteriza por un crecimiento continuado de la población municipal, con un salto muy importante en el decenio 1960-70, en que registra su mayor intensidad, con una tasa de crecimiento acumulado de 4,428\%o. Este ritmo excepcionalmente elevado de crecimiento -el mayor de la centuria-se interrumpe de forma brusca en el decenio 1970-81, registrando incluso tasas negativas (tca. -0,302); sorprende mucho más cuando este retroceso demográfico coincide con la década en que la construcción de vivienda destinada a población permanente crece con mayor intensidad. Comoquiera que no hemos hallado circunstancias o hechos objetivos en la dinámica social, económica y urbanística, capaces de justificar o explicar este retroceso, al menos en parte, este se ha de imputar a desajustes en las fuentes estadísticas (cuadros III y IV).

\begin{tabular}{lccccc}
\hline \multicolumn{6}{c}{ CUADRO III. EVOLUCIÓN DE LA POBLACIÓN DEL PUERTO DE LA CRUZ } \\
EN EL PERÍODO 1940-1981 \\
\hline ENTIDADES DE POBLACIÓN & 1940 & 1950 & 1960 & 1970 & 1981 \\
\hline Puerto Cruz centro & 5156 & 5637 & 7127 & 13246 & 13711 \\
\hline Periferia urbana & 5539 & 6472 & 7143 & 8763 & 7642 \\
\hline TOTAL & $\mathbf{1 0 6 9 5}$ & $\mathbf{1 2} \mathbf{1 0 9}$ & $\mathbf{1 4 2 7 0}$ & $\mathbf{2 2 ~ 0 0 9}$ & $\mathbf{2 1 3 5 3}$ \\
\hline
\end{tabular}

Fuente: Instituto Nacional de Estadística. Nomenclátores de 1940, 1950, 1960, 1970 y 1981. Elaboración propia.

\begin{tabular}{lccccc}
\hline \multicolumn{5}{c}{ CUADRO IV. NÚMERO DE EDIFICIOS DE VIVIENDAS EN EL PERÍODO } & 1940-1981 \\
\hline & 1940 & 1950 & 1960 & 1970 & 1981 \\
\hline Puerto Cruz centro* & 809 & 844 & 1279 & 2668 & 6534 \\
\hline Periferia urbana & 883 & 976 & 1298 & 1898 & 2528 \\
\hline TOTAL & $\mathbf{1 6 9 2}$ & $\mathbf{1 8 2 0}$ & $\mathbf{2 5 7 7}$ & $\mathbf{4 5 6 6}$ & $\mathbf{9 0 6 2}$ \\
\hline $\begin{array}{l}\text { * Puerto de la Cruz centro incluye, además del casco urbano, los ensanches occidentales (polígono residencial El Tejar y polígono turístico de San } \\
\text { Felipe) y oriental (Martiánez). } \\
\text { Fuente: Instituto Nacional de Estadística. Nomenclátores de 1940, 1950, 1960, 1970 y 1981. Elaboración propia. }\end{array}$
\end{tabular}

Como en el apartado anterior, el desarrollo expositivo incorpora una breve introducción de la política pública de vivienda desarrollada en el Puerto de la Cruz, entre 1939 y 1978, que incluye las medidas implementadas en la materia, tanto de carácter exclusivamente municipal como las promociones del Ayuntamiento ejecutadas en colaboración con otras administraciones, en el marco de leyes y planes de vivienda supramunicipales. Desde este marco global, se aborda el análisis de la promoción y creación de ciudadelas como una línea más de la política municipal

11 TATjer, M., op. cit., p. 4. 
de vivienda, en la que trataremos las estrechas interconexiones entre las distintas medidas aplicadas.

Con carácter general, como venimos señalando, la política de vivienda en el franquismo es un argumento político nuclear, consecuencia del apoyo ideológico a la familia, receptáculo de las esencias espirituales y conservadoras de la sociedad. Era frecuente en los discursos políticos de entonces -como ocurre en sectores políticos conservadores en la actualidad-, hacer referencia al hogar, además naturalmente de aquellos en que se trataban específicamente cuestiones relacionadas con la vivienda social ${ }^{12}$. El apoyo público a la vivienda de promoción privada entre 1940 y 1980 estuvo condicionado, junto con los objetivos sociales que le son inherentes, por el papel económico que la actividad inmobiliaria desempeñó en la estructura económica y por factores de carácter político ${ }^{13}$.

En lo que al Puerto de la Cruz se refiere, el período resulta complejo, por hallarse en un proceso de rápida e intensa transformación socioeconómica del municipio, inmerso en una dinámica urbanística sometida a los intereses especulativos de una iniciativa privada centrada en la demanda del mercado inmobiliario turístico; mientras la resolución del importante problema de la vivienda en el municipio se canaliza a través de una política de vivienda dependiente de la estatal.

En todo caso, la documentación del archivo municipal ilustra la centralidad que el Ayuntamiento del Puerto de la Cruz asigna al problema de la vivienda. Un informe-moción sobre la cuestión, fechado en 1954, de los concejales Pablo Hernández Herrera (delegado local de Sindicatos) y Antonio León González (presidente de la Sección Social Local de Sindicatos), recoge aspectos nucleares que sitúan la cuestión:

- En primer lugar, confiere al problema un ámbito nacional, y analiza la evolución de la construcción de viviendas en el municipio entre 1900 y $1950^{14}$, llegando a la conclusión -estimada en el supuesto de una composición familiar media de cinco miembros/unidad familiar- de que, en 1953, el déficit municipal asciende a 770 viviendas $^{15}$.

- Reconoce el escaso atractivo que representa la construcción de viviendas para familias humildes por la iniciativa privada. Al tiempo que enumera el con-

12 Cfr. Fernández Anta, Dolores, López Portero, Elena y Lucas Viña, M. ${ }^{a}$ del Mar, «La Vivienda en Madrid (1939-1961)». Trabajo dirigido por Dr. Luis Enrique Otero Carvajal. Madrid, ss. XXI-XX. Facultad de Geografía e Historia (curso 1998-99). Universidad Complutense de Madrid. Disponible en pdf en http://www.academia.edu/6174285/La vivienda en Madrid 1939-1961.

13 Parreño Castellano, Juan Manuel, «El destino social de la vivienda protegida de promoción privada: El caso de Las Palmas de Gran Canaria (1940-1978)». Scripta Nova. Revista Electrónica de Geografía y Ciencias Sociales. Universidad de Barcelona. vol. vir, n. ${ }^{\circ}$ 146. 1 de agosto de 2003. p. 1.

${ }_{14}$ Los datos utilizados por el informe no se corresponden con los recogidos en los nomenclátores, transcritos en los cuadros expuestos más arriba. No obstante, la tendencia sí es muy similar.

${ }^{15}$ AMPC. Informe Sobre la situación de la Vivienda en el Puerto de la Cruz. Acuerdos plenarios. Sesión plenaria de 2 de septiembre de 1954, libro 577. fol. 174-177. 
junto de medidas políticas y legislativas promovidas por el Gobierno para apoyar la construcción de viviendas de tipo social ${ }^{16}$.

- Por último, centra el origen del problema municipal en la falta de suelo, instando al Ayuntamiento a su adquisición, en primer lugar por la vía de la negociación o -si es necesario- en segunda instancia a través de la expropiación, aplicando la Ley de 7 de octubre de 1939.

- Concluye demandando que, pese a las dificultades financieras del Ayuntamiento para la adquisición de terrenos, otorgue prioridad al problema de la vivienda ${ }^{17}$.

El informe-moción sitúa con sorprendente precisión el problema en el marco municipal, y pone de manifiesto -aunque no de forma explícita- la ineficacia de las políticas de viviendas promovidas entre 1937-1953, período en que, según cálculo de los impulsores de la moción, se construyeron 62 viviendas, muy por debajo de las edificadas antes de la instauración de la dictadura: 510 viviendas ${ }^{18}$, distribuidas de la siguiente forma:

- 1900-1918: 150.

- 1919-1936: 360 .

En materia de vivienda, la dinámica seguida por el Puerto de la Cruz es similar a la de buena parte del Archipiélago. Parreño Castellano y Díaz Hernández señalan que la acelerada construcción de la ciudad desde finales de los cincuenta está íntimamente relacionada con la preexistencia de una etapa de dos décadas en la que la crisis económica y constructora puso las bases del aumento posterior. Asimismo, la autarquía contribuyó a generar un enorme déficit de vivienda cuya satisfacción justificó un modelo de expansión masivo y de baja calidad a la par que posibilitó un cambio de estructura en el sector promotor-constructor. Según Parreño Castellano y Díaz Hernández, el crecimiento inmobiliario de los sesenta sólo se puede entender si tenemos en cuenta el efecto de la política económica en los cuarenta y en los cincuenta ${ }^{19}$.

En línea con este marco general, la información disponible, a escala municipal, confirma que la evolución del parque de viviendas creció de forma ininterrumpida durante los cuarenta ańos de franquismo, registrando su menor intensidad en el decenio de 1940-1950 -autarquía-, y en la década de 1960-1970 el más elevado; especialmente, en este último (cuadro III). Esta evolución establece un lógico paralelismo entre la construcción de viviendas, crecimiento de la población y actividad

16 Idem.

17 Ibidem.

18 Ibidem.

19 Díaz Hernández, Ramón y Parreño Castellano, Juan Manuel, «La Política Económica. La Construcción de Vivienda y La Producción de la Ciudad en España (1939-1975)». Scripta Nova. Revista electrónica de Geografía y Ciencias Sociales. Universidad de Barcelona, vol. x. n. 218. 1 de agosto de 2006. pp. 3-4. 
turística, coincidiendo con el momento de máxima intensidad en los años sesenta y primer lustro de los setenta.

Las nuevas viviendas se concentran mayoritariamente en el centro urbano -que engloba los ensanches occidentales (polígonos residencial El Tejar [1963] y turístico de San Felipe [1975]) y oriental (Martiánez)-. El resto de la población y de las viviendas se distribuyen en los barrios de la periferia, que han mutado su carácter agrícola, transformándose en áreas urbanas (San Antonio-Esquilón, La Paz, La Vera, Las Arenas, Calle Nueva, Punta Brava, El Durazno, San Nicolás, etc.). Las insuficiencias de las fuentes restan interés a la variable espacial en el análisis de la información estadística, al menos de los años sesenta y setenta.

La importante actividad en materia de vivienda desarrollada a lo largo de los años del franquismo, como venimos señalando, se sustentó fundamentalmente en la canalización de las medidas y planes promovidos y financiados por la Administración del Estado. Básicamente el déficit municipal de viviendas es abordado a través de tres líneas de intervención: 1) programas de viviendas sociales y viviendas de protección oficial (VPO); 2) reparto de solares; 3) ciudadelas.

\section{VIVIENDAS SOCIALES Y VPO}

A mediados de la década de los cincuenta, con la aprobación de la Ley de 15 de julio de 1954 sobre Viviendas de Renta Limitada, y el imprescindible complemento, en julio de 1955, del Plan Nacional de la Vivienda, el Ayuntamiento inició la promoción de viviendas sociales en los Llanos de San Felipe-El Tejar, en la margen oriental del barranco de San Felipe. El Consistorio es promotor urbanístico que da respuesta a la demanda de vivienda, fijada en el «Informe Sobre la situación de la Vivienda en el Puerto de la Cruz de $1954^{20}{ }^{\text {» en }} 770$ viviendas. Ya en 1951 la Obra Social del Movimiento de FET y de las JONS promovió y construyó diecinueve viviendas económicas en el barrio de Punta Brava, en las calles Romén y Víctor Machado. A partir de 1955, en colaboración con el Instituto Nacional de la Vivienda y la Obra Sindical del Hogar y Arquitectura, en el período de 1955-1960, se construyen los grupos de viviendas sociales de San Felipe, Carlos Arias, Solís Ruiz y Nuestra Señora de La Luz, que suman un total de trescientas treinta viviendas. Habría que añadir, ya fallecido Franco, el grupo de la Cruz de Pino, en 1978, de ciento noventa y dos viviendas, y el grupo de El Carmen, en La Vera que hubo de ser desalojado por aluminosis ${ }^{21}$. En total fueron construidas quinientas cuarenta y una viviendas sociales, en el período de 1939-1978, de las que una buena parte se destina a alojar a familias residentes en las ciudadelas del municipio. A esto se han

${ }^{20}$ AMPC. Informe Sobre la situación de la Vivienda en el Puerto de la Cruz. Acuerdos plenarios. Sesión plenaria de 2 de septiembre de 1954, libro 577. fol. 174-177.

${ }^{21}$ Barroso Hernández, Nicolás D., Puerto de la Cruz: Desarrollo Urbano y Organización del Espacio..., op. cit., pp. 383-384. 
de añadir sesenta viviendas construidas por el Ayuntamiento en colaboración con la Gerencia de Urbanización del Ministerio de la Vivienda en el polígono El Tejar: Santiago Apóstol I (10 viv., 1967) y Santiago Apóstol II (14 viv., 1977) y San Valentín (36 viv., 1968) $)^{22}$.

El desarrollo de este programa de promoción y construcción de viviendas sociales guarda una estrecha relación con la vivienda colectiva obrera, en la medida en que las ciudadelas son un centro de preocupación de los gobiernos municipales -especialmente las ubicadas en el centro urbano-, y su erradicación está muy presente en las iniciativas de promoción y construcción de viviendas sociales en los años cincuenta y sesenta. Una moción de la Alcaldía de 1953 avala esta conexión, incorporando argumentos que obviando la necesidad urgente de superar las precarias condiciones de salubridad y hacinamiento en que viven sus residentes, centra la prioridad en el dańo que ocasiona a la imagen del municipio la presencia de estas familias en el centro de la ciudad:

El Sr. Alcalde manifiesta que sin duda alguna, este Municipio es el centro turístico más importante del archipiélago canario, ya que es el más visitado por los extranjeros, [...], lo que obliga a esta Corporación que se ocupe de una manera preferente y especial en mantener y elevar este prestigio [...]. Con motivo del temporal que azotó este Valle de la Orotava el día quince de enero último, quedaron sin vivienda gran número de familias humildes y modestas, lo que obligó a este Ayuntamiento a alojarlas en edificios situados en el centro de esta población, uno de ellos en el antiguo convento de San Francisco, muy próximo a los Hoteles de Turismo «Monopol» y «Marquesa», lindante con la Iglesia del mismo nombre donde cumplen sus deberes religiosos los turistas que profesan la religión católica y en las cercanías del edificio de la sucursal del Banco Hispano Americano, del Instituto de Estudios Hispánicos y del de Correos y Telégrafos, lugares muy visitados por los extranjeros. Con el fin de proceder a la eliminación de estas familias del centro del casco urbano - continua manifestando el Señor Presidente- había encargado [...], un proyecto de Urbanización de la Zona del Barranco de San Felipe y construcción en la misma de ciento cincuenta viviendas ${ }^{23}$.

Incluso, un año más tarde, la Alcaldía reitera idéntico argumento con motivo de la visita del inspector de la Vivienda de la Dirección General de Regiones Devas$\operatorname{tadas}^{24}$, a quien se le demanda la colaboración del departamento en la construcción de viviendas económicas, donde alojar a los vecinos de las ciudadelas del centro urbano. De cualquier modo, la erradicación de las ciudadelas del centro del municipio fue objetivo central de las políticas municipales, y estuvo presente en las iniciativas de adquisición y urbanización de suelo para la construcción de viviendas sociales hasta 1978. $161 \mathrm{vt}^{\circ}-162$

22 Barroso Hernández, Nicolás D., op. cit., pp. 125-128 y 185.

23 AMPC. Acuerdos plenarios. Sesión plenaria de 21 de agosto de 1953, libro 577. fol.

${ }^{24}$ Idem. Acuerdos plenarios. Sesión plenaria de 27 de septiembre de 1954, libro 577. fol. 179. 


\section{REPARTO DE SOLARES}

Asimismo, durante el franquismo se mantiene la política de «reparto de solares» en suelo público con destino a la autoconstrucción de vivienda. No obstante, la disponibilidad de suelo es escasa, por lo que se circunscribe a áreas muy concretas del término municipal:

- Extremo noroccidental de la calle Mequinez, cerca del Peńón del Fraile.

- Punta Brava que, en las décadas de los cincuenta, sesenta y setenta se constituye en uno de los barrios más dinámicos y populosos del municipio.

Sin duda, la autoconstrucción está presente en otras áreas de municipio, pero no como resultado de la intervención de la administración municipal.

\section{CIUDADELAS}

Concluida la Guerra Civil, se mantienen en funcionamiento las ciudadelas de Mequinez, Los Cubanos y el convento de San Francisco.

En las décadas de los cincuenta y los sesenta, se crean nuevas viviendas colectivas obreras, con la novedad, como se ha señalado, de que ahora son de promoción pública. En efecto, todas las ciudadelas creadas en este período forman parte de las medidas promovidas por la administración municipal franquista como solución habitacional de emergencia a la demanda de vivienda de los sectores sociales más humildes. Los beneficiarios de estas medidas se ajustan a un perfil social similar a los ya existentes, a los que se unen familias que han perdido su vivienda como resultado de calamidades o catástrofes (temporales, avenidas de barrancos y crecidas del mar), así como desahucios y expropiaciones judiciales, como daño colateral del incremento exponencial del precio del suelo generado por el boom turístico y el proceso urbanizador, cuyo coste social es asumido por el erario público «municipal».

El archivo municipal apenas dispone de información documental o gráfica relativa a las ciudadelas. Son soluciones habitacionales, implementadas como respuesta sistemática e institucional de la administración municipal ante las situaciones de emergencia que propone la dinámica social. En este sentido, con independencia del tratamiento administrativo aplicado, se trata de un fenómeno habitacional que adquirió proporciones socialmente relevantes en el balance final de la política de vivienda del Puerto de la Cruz. El Ayuntamiento, desbordado e incapaz de resolver el problema de la vivienda de forma adecuada y satisfactoria, se ve impelido a promover la solución habitacional de las ciudadelas, que, no obstante ello y la magnitud alcanzada, han sido objeto de una gestión técnico-administrativa «marginal». Ello explica que buena parte del contenido de esta investigación ha sido elaborado a partir de referencias documentales indirectas y artículos de prensa que abordan la cuestión. Asimismo, hemos acudido a testimonios orales y escritos recogidos de personas que vivieron en ellas o que las conocieron personalmente. Las cuestiones formuladas a los informantes son muy básicas, como datos acerca de las fechas del 
inicio y cierre de la vivienda colectiva, número y disposición de las dependencias, superficie de cada vivienda, número de retretes y dotación higiénico-sanitaria del inmueble, lavaderos, número de familias y/o personas y toda aquella información que considerásemos de interés.

Por último, hemos incorporado nuestro conocimiento y experiencia personal, pues tuvimos la oportunidad de conocer directamente y en pleno uso y funcionamiento la mayor parte de las ciudadelas del municipio, entre 1955 y su definitiva erradicación en 1978 .

Hechas estas aclaraciones previas, tenemos que en el Puerto de la Cruz coexistieron, hasta finales de los años setenta, las ciudadelas que se relacionan:
a. Mequinez.
b. Los Cubanos.
c. El Convoy.
d. El Chavito.
e. Casa Cullen.
f. Convento de San Francisco.
g. El Lazareto.
h. Falange.
i. Empaquetado Yeoward.

\section{a. La Ciudadela de Mequinez}

Esta ciudadela (foto 3), de titularidad privada, se mantiene en funcionamiento después de la Guerra Civil y, como el resto, permanece activa como vivienda colectiva hasta los años setenta; posiblemente, hasta 1978. En 1960 residen en la misma 16 familias y 57 personas ${ }^{25}$.

\section{b. Los Cubanos}

Se mantiene en funcionamiento durante el franquismo, y consta que en 1960 residen en este edificio nueve familias y 40 personas $^{26}$. Cuando se cerró en 1978 los inquilinos fueron realojados en el Grupo de Viviendas Sociales de la Cruz del Pino. La precariedad de las condiciones higiénico-sanitarias manifestadas por don Manuel (Los Cubanos) y doña Concha (Mequinez) son matizadas, sin embargo, por informantes más jóvenes que vivieron o conocieron la ciudadela en momentos previos a su clausura, que, sin cuestionarlas, no ponen especial énfasis en este aspecto.

25 Hernández Castilla, José Melchor, «Las ciudadelas del Puerto de la Cruz, del siglo xx», La Prensa (revista semanal de El Día), 14 de septiembre de 2014, p. 1.

26 Idem. 


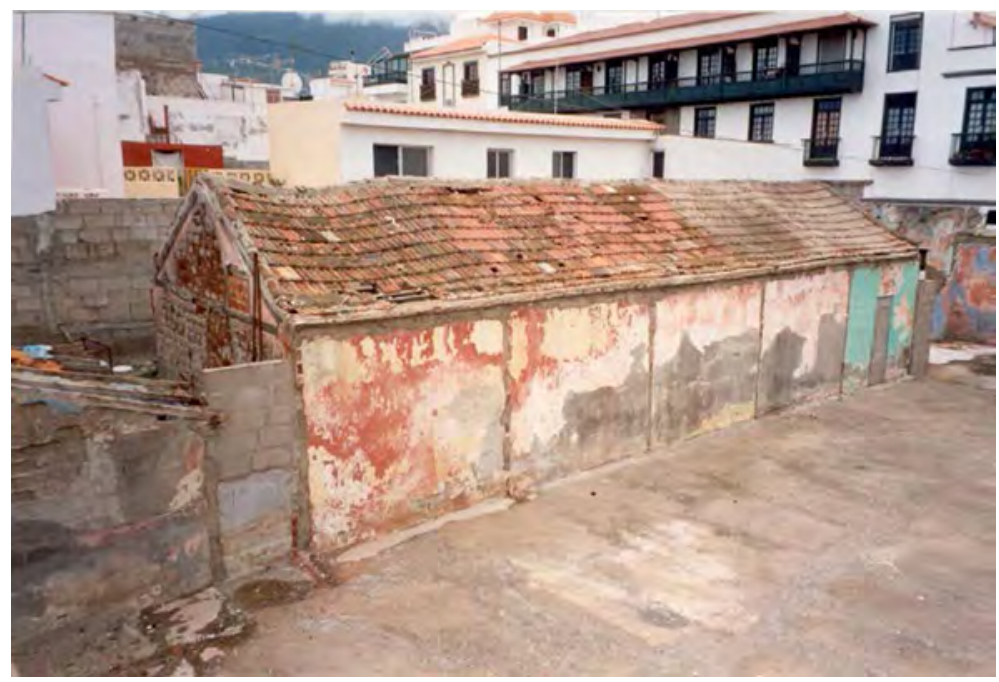

Foto 3. Situación actual de la ciudadela de Mequinez. En primer plano, vista de una nave de la ciudadela. Al fondo, el edificio construido en la parcela donde estuvo la ciudadela Los Cubanos.

\section{c. El Convoy}

Es una ciudadela generada a partir del reaprovechamiento y adaptación de un empaquetado de plátanos en desuso, situado entre las calles Pérez Zamora n. ${ }^{\circ} 40$ y La Verdad n. ${ }^{\circ}$ 19. Sus propietarios (don Vicente y don Sebastián Fernández Pérez de Celis y otros) ofertan el inmueble al Ayuntamiento en noviembre de 1952, aunque es en junio de 1954 cuando se inician negociaciones y en febrero de 1956 se acuerda la compra del inmueble «seńalado bajo los números de policía 38, 40 y 42 de la calle Pérez Zamora, con una superficie de $1078,5 \mathrm{~m}^{2} »^{27}$. Unos meses más tarde se realizan obras para la ampliación y mejora de los equipamientos higiénico-sanitarios construyendo quince nuevos habitáculos: «Este se hizo porque nos encontramos con el grave problema planteado con motivo de varios desahucios judiciales y cuyas familias pobres no encontraban sitio donde instalarse ${ }^{28}$. En todo caso, se infiere de la lectura de los acuerdos que, previo a su adquisición por el Ayuntamiento, el inmueble desempeńa funciones de ciudadela.

27 AMPC. Actas del Pleno del Ayuntamiento, sesión extraordinaria de 16 de febrero de 1956, libro 578-L (1955-1958), fls. 76 vta., 77 y 77 vta. 1956.

28 AMPC. Actas del Pleno del Ayuntamiento, sesión extraordinaria de 15 de junio de 1956, libro 578-L (1955-1958), Als. 93 y 93 vta. 1956. 


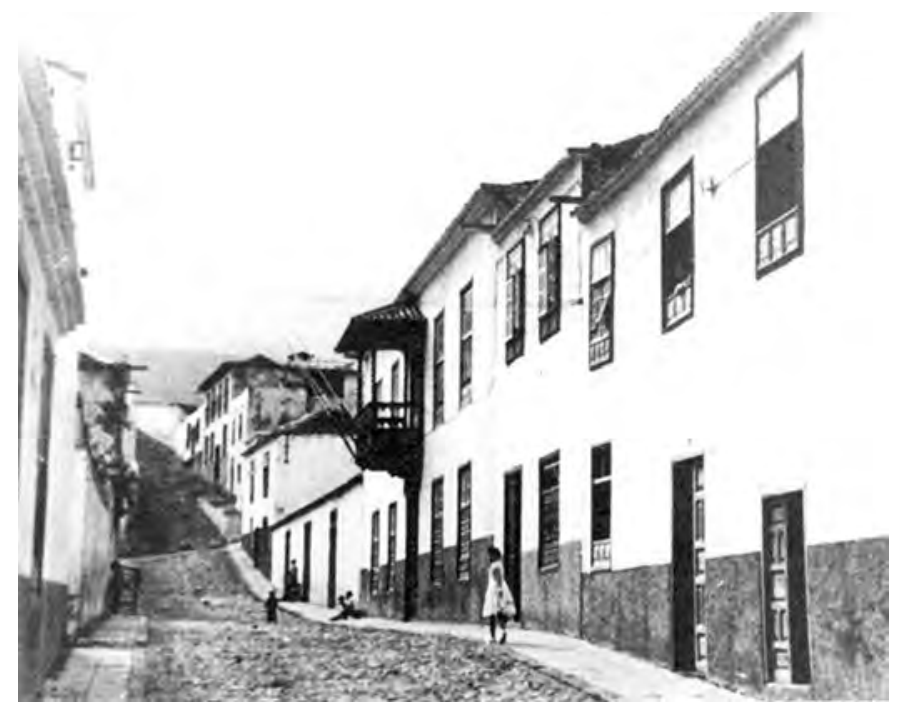

Foto 4. Ciudadela de El Convoy. Fachada a la calle de Pérez Zamora. Edificio de una sola planta, situado a la derecha de la imagen. Se pueden ver las tres puertas de los tres módulos de viviendas con acceso a la calle.

Se trata de naves o salones rectangulares compartimentados con tabicas, formando alojamientos de una o dos piezas que servían de dormitorio, comedor y cocina. Esta ciudadela fue conocida popularmente como El Convoy (foto 4). Según referencias orales, estaba formada por cuatro módulos, con conexión exterior independiente (una con fachada a la calle de La Verdad y tres a la calle de Pérez Zamora), en cada una de las cuales la superficie y forma de los habitáculos presenta diferencias. Según el padrón de habitantes de 1965 en el inmueble residen 35 familias; 24 en Pérez Zamora n. ${ }^{\circ} 40$ y 11 en La Verdad n. ${ }^{\circ} 19$.

- El módulo abierto a la calle de La Verdad contaba con alojamientos, separados por un pasillo central, a cuyos lados se disponían dos hileras con ocho habitáculos; los muros de separación entre las viviendas no alcanzan el techo, por lo que eran vulnerables y carentes de las mínimas condiciones de intimidad. La superficie total de cada uno los informantes la sitúan en torno a los $40 \mathrm{~m}^{2}$, divididos en su interior -con cartón piedra o saco de pita pintado- en una pequeña cocina y dos dormitorios. Las letrinas o baños eran comunes, y contaba con una pila de agua amplia como lavadero de la ropa para todos los residentes.

- El sector con fachada a la calle Pérez Zamora estaba dividido en tres módulos con 19 viviendas en total, dispuestas en torno a sus respectivos pasillos. La superficie de cada una era variable, aunque su media podía ser de, aproximadamente, $50 \mathrm{~m}^{2}$, y las divisiones interiores eran de ladrillo. Los tabiques de 


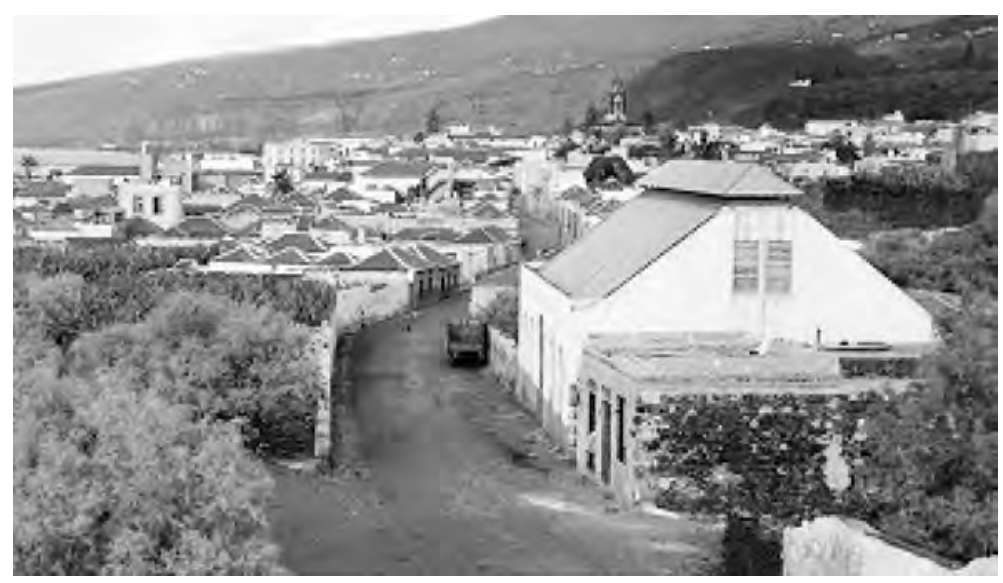

Foto 5. Ciudadela de El Chavito. Calle San Felipe, en la zona del Peńón del Fraile. El edificio de la ciudadela es el de la derecha de la imagen, con cubierta a dos aguas. Posiblemente, la fotografía fue tomada cuando aún era un centro de producción de energía eléctrica.

división de las viviendas llegaban hasta la cubierta. Los informantes señalan que contaban con suministro de energía eléctrica en cada vivienda, pero no de agua corriente; se tomaba de los retretes o del estaque. Disponían de tres retretes - uno por cada módulo de siete, siete y cinco viviendas cada uno-. Las condiciones de hacinamiento son muy elevadas, en la medida en que muchas de las familias residentes son muy prolíficas, comportamiento reproductivo muy común en los años cincuenta y sesenta.

Las familias de la ciudadela El Convoy fueron progresivamente realojadas en los grupos de viviendas sociales del polígono residencial El Tejar y en La Vera ${ }^{29}$, desde finales de los años sesenta y a lo largo de la década de los setenta.

\section{d. El Chavito}

Es una ciudadela (foto 5) situada en el límite occidental de la calle de San Felipe, próxima al Peńón del Fraile; aunque no es de las más populares, hemos podido reconstruir algunos aspectos sobre las condiciones de vida de sus residentes a través de testimonios de personas que conocieron la vivienda. Sabemos que el edificio -antes de la Guerra Civil-sirvió de central eléctrica de carbón. Después de

29 Barroso Hernández, Nicolás D., op. cit.: el grupo de viviendas de El Carmen, construido antes del desarrollo del polígono 1, sector 9 de La Vera, es posterior a la aprobación del PGOU de 1974 y sus adaptaciones de 1978 y 1979. 


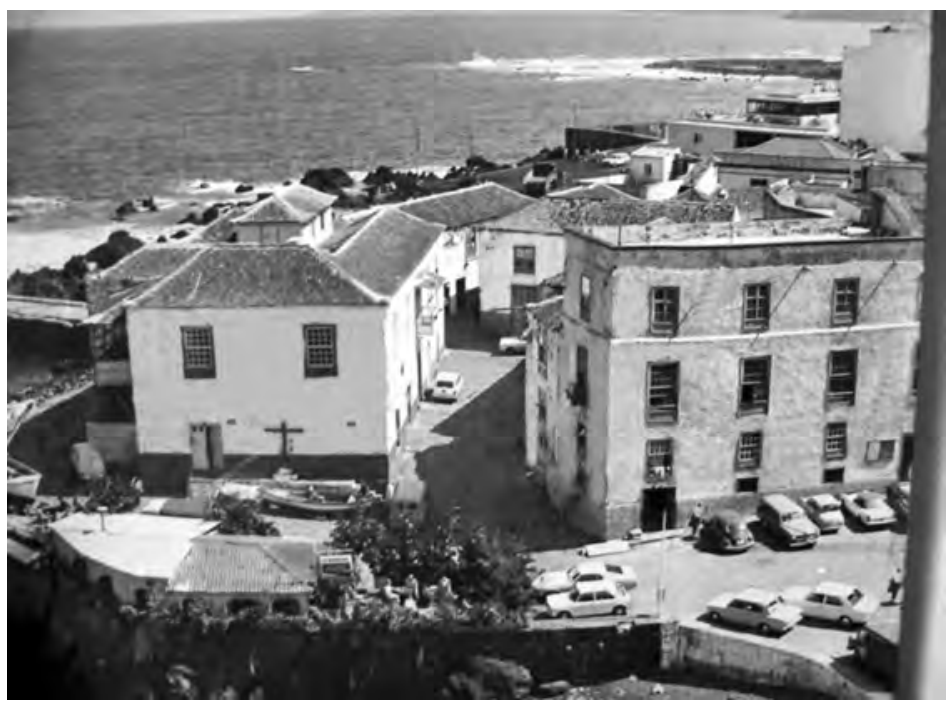

Foto 6. Ciudadela casa Cullen, edificio de cuatro plantas, situado a la derecha de la imagen.

1939, fue habilitada como vivienda colectiva obrera, función que desempeñó hasta 1956. El inmueble era de titularidad privada -concretamente, de don Eduardo Calderón-, aunque estaba arrendado por el Ayuntamiento. Según testimonio oral, el interior se hallaba dividido en ocho compartimentos o habitáculos, donde residieron otras tantas familias, integradas por unas cincuenta personas ${ }^{30}$. No disponía de agua corriente ni de energía eléctrica. Había un solo retrete común para todos los residentes y una pila de lavar. En 1956, según nuestro informante, fueron realojados en el grupo de viviendas sociales «Barriada de San Felipe».

\section{e. Casa Cullen}

Se trata de una casa canaria del siglo XviII (foto 6) de titularidad privada, que formaba parte del espléndido conjunto urbano del muelle del Puerto de la Cruz -hoy desaparecida-. Disponemos de escasa información, aunque sí es de dominio público que sirvió de ciudadela hasta los años setenta. Un informe municipal no fechado, pero que podemos situar en los años cincuenta, le asigna doce viviendas y

30 Nuestro informante-don Germán García González- recordaba los nombres de muchas de las familias y de sus hijos/as; entre otros citó a dońa Lucia (madre del "Chavito», apodo que puede estar en el origen de la denominación del inmueble), etc. Un documento del AMPC, signatura 1705, señala que contaba con 13 viviendas y 77 residentes. 
41 residentes $^{31}$. Tiempo después, un artículo publicado en la Revista Local en 1984 señala que los ocupantes de este inmueble fueron realojados en el grupo de viviendas de la Cruz del Pino en $1978^{32}$.

\section{f. Convento de San Francisco}

Las deficiencias del edificio y su precaria situación higiénica y de salubridad denunciada en 1912, y el informe elaborado por el comisario don Pedro Corrales Casado $^{33}$, de 8 de octubre de 1912, concluyeron con el traslado provisional de los ocupantes del inmueble, para la ejecución de obras de reparación. Tras la Guerra Civil continuó desempeñando la función de ciudadela y en la década de los cincuenta el edificio pasó a propiedad del Ayuntamiento. En junio de 1954 la familia Llombet -propietaria del edificio- oferta al Ayuntamiento el «inmueble conocido por la Ciudadela de San Francisco (foto 7) con una superficie de 3041,10 metros cuadrados» por el precio de 400000 pesetas $^{34}$. La documentación que acompaña la negociación y acuerdo de compra hace referencia a que «el mismo es morada de innumerables familias ${ }^{35}$. Ambos documentos confirman que la función de vivienda obrera colectiva no se interrumpió tras las reparaciones de 1912, toda vez que está arrendado por el Ayuntamiento y combina la doble función de alojamiento de policías («guardias») municipales y empleados públicos ${ }^{36}$ con bajos salarios y de familias obreras en situación de precariedad. Como se desprende del informe emitido por el comisario en 1912, la compartimentación de habitáculos se adaptó a la estructura primitiva del edificio. Se trata del alojamiento colectivo más complejo, porque compatibiliza el uso de vivienda de empleados públicos y de ciudadela abierta a población vulnerable. Sabemos que la ocupación del edificio se incrementó con el realojo de las familias afectadas por un temporal en enero de $1953^{37}$. Los elementos for-

${ }^{31}$ AMPC. Relación de viviendas. Signatura 1705. 1950-55.

32 «Desde el Estado con amor». Revista Local. n. ${ }^{\circ} 18$. Ayuntamiento del Puerto de la Cruz. Diciembre de 1984. pp.17-23.

33 AMPC. Beneficencia, Sanidad y Calamidades Pública, legajo 60, Expediente n. ${ }^{\circ} 14$ (1911-1912). Expediente instruido, en vista de denuncia formulada sobre malas condiciones higiénicas y de salubridad que reúne la casa de «Depósito Municipal», situada en la calle de «Agustín de Bethencourt» (1911-1912).

${ }_{34}$ AMPC. Actas del Pleno del Ayuntamiento, sesión extraordinaria de 2 de agosto de 1954, libro 577-L (1954-1955), fls. 160 y 161. 1954.

35 AMPC. Actas del Pleno del Ayuntamiento, sesión extraordinaria de 8 de junio de 1954, libro 577-L (1954-1955), fls. 154 vta. 1954

${ }^{36}$ La Administración pública tiene la obligación de proporcionar alojamiento a los funcionarios civiles del Estado y algunos empleados públicos. Hasta los años ochenta (1984-85), en que fueron suprimidos, determinados funcionarios y empleados públicos tenían a su disposición una vivienda municipal. La legislación que regula este derecho es muy amplia y compleja, porque incluye educación, justicia, correos, cuerpos de policía -municipal, nacional y guardia civil, militar, etc.-.

37 AMPC. Acuerdos plenarios. Sesión plenaria de 21 de agosto de 1953, libro 577. fols. $161 \mathrm{vt}^{\mathrm{o}}$ - 162. «Con motivo del temporal que azotó este Valle de la Orotava el día quince de enero 


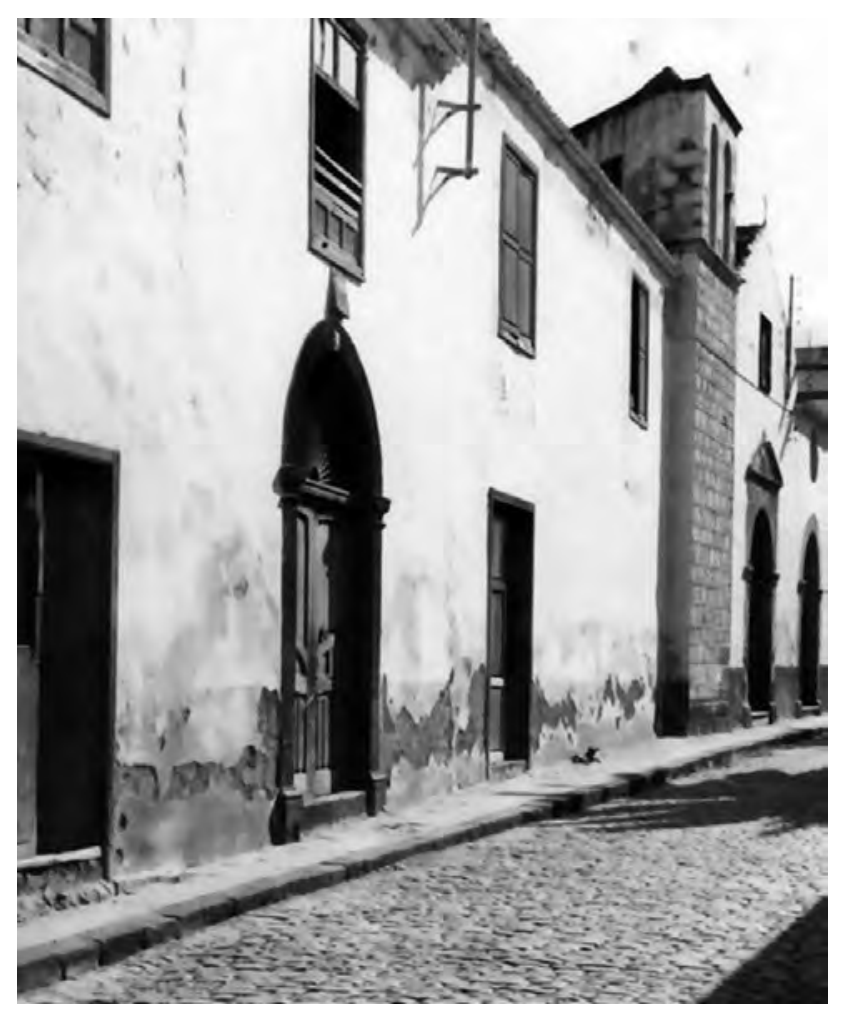

Foto 7. Ciudadela del convento de San Francisco. Fachada a la calle San Juan, destinada a vivienda de población obrera, en general. Al fondo la iglesia de San Francisco.

males y funcionales e incluso la documentación asignan la condición de ciudadela al convento franciscano. Sus residentes viven en condiciones de hacinamiento, con un sistema de saneamiento y sanitario comunitario, formado por una pila central de agua corriente y dos letrinas. Además, compatibilizaba el uso habitacional con el de sede del calabozo municipal. Documentación del archivo municipal de los años cincuenta, incluye una relación de ciudadelas, entre ellas el convento de San Francisco, señalando que el sector de la fachada oriental (calle Agustín de Bethencourt n. ${ }^{\circ} 8$ ) está destinado a empleados públicos, y residen 13 familias y 62 individuos; y en la fachada occidental (calle de San Juan n. ${ }^{\circ}$ ) hay 36 viviendas y 183 personas $^{38}$. El edificio quedó destruido por un incendio en 1966, por lo que sus residentes, o al

último, quedaron sin vivienda gran número de familias humildes y modestas, lo que obligó a este Ayuntamiento a alojarlas en edificios situados en el centro de esta población, uno de ellos en el antiguo convento de San Francisco».

38 Idem. Relación de viviendas. Signatura 1705. 1950-1955. 


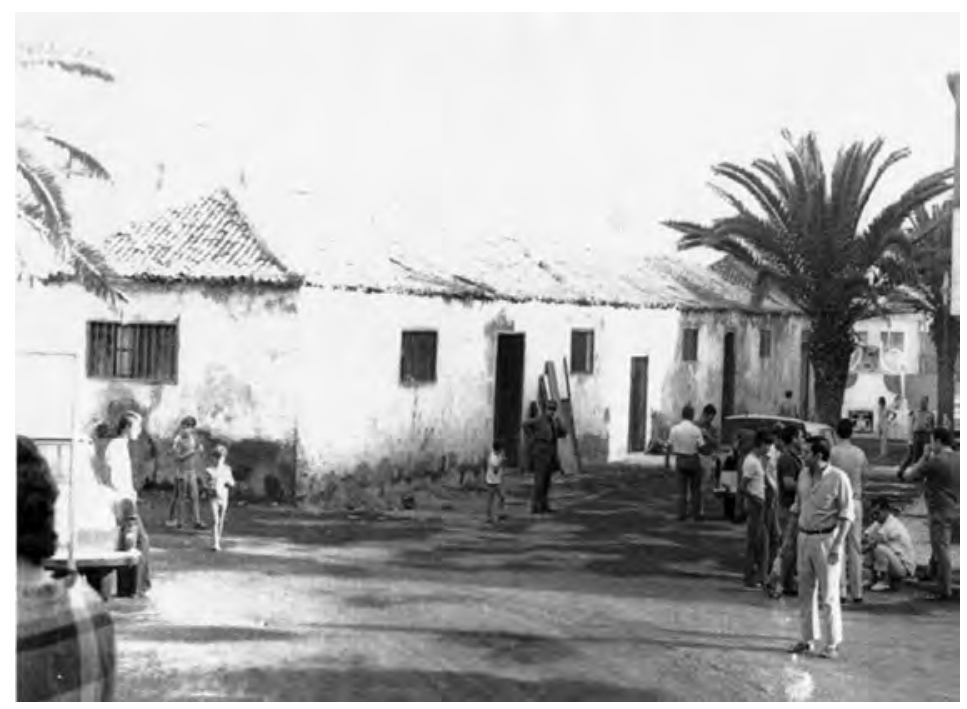

Foto 8. El Lazareto, situado en el barrio de Punta Brava.

menos una parte de ellos, fueron realojados provisionalmente en el empaquetado de Yeoward, que, de este modo, pasa a convertirse en una ciudadela de tránsito hasta los años setenta. Por lo tanto, el convento de San Francisco es una vivienda colectiva de gestión pública, que proporciona alojamiento, de forma segregada, a empleados públicos y a familias obreras precarias. En todo caso, los empleados públicos de categoría y cualificación media y superior son alojados en otro tipo de vivienda (profesionales de educación, justicia, correos, etc.).

\section{g. El Lazareto}

En torno a 1833 se construye El Lazareto (foto 8) en el barrio de Punta Brava, edificio destinado al desempeño de las funciones inherentes a este tipo de infraestructura sanitaria. En estos momentos se hallaba dentro de la jurisdicción municipal de Los Realejos ${ }^{39}$, alejado de las áreas urbanizadas y, en consecuencia, cumpliendo con las preceptivas condiciones de aislamiento. Sabemos que en 1905 deja

39 Barroso Hernández, N.D., op. cit., p. 191. Tras un lago conflicto jurisdiccional que ocupa la primera mitad del siglo xIx, en 1847, el municipio del Puerto de la Cruz incorpora un conjunto de territorios, entre los que se encuentra Punta Brava (en Hernández González, Manuel y Arbelo García, Adolfo, Elecciones Generales en el Valle de la Orotava 1841-1899, La Orotava, 1983, pp. 109-116). 
de desempeñar su función original y se encuentra abandonado, porque un exalcalde - ya del Puerto de la Cruz- manifiesta haber cedido temporalmente el edificio a una empresa agrícola para su utilización como empaquetado de plátanos ${ }^{40}$. Según Hernández Castilla, en 1941 comienza su utilización como ciudadela ${ }^{41}$.

No se dispone de información relativa a sus características físicas (superficie, número de alojamientos, retretes, cocina, etc.). Benjamín Afonso, en 1970, describe cómo un «viejo inmueble de una planta, cubierto con teja del país, vino a convertirse por consecuencia del problema de escasez de vivienda de renta módica, en una especie de ciudadela.... ${ }^{42}$. En ese año $-1970-$, señala, «viven unos diez matrimonios con hijos, en condiciones no muy holgadas, por cierto, ni con las mínimas comodidades exigibles para una existencia higiénica y decorosa» ${ }^{43}$. El padrón de 1965 le asigna 13 familias (47 personas) y fue clausurada, según Hernández Castilla, en $1972^{44}$.

\section{h. Edificio de Falange}

Se trata de un edificio de titularidad privada, situado en la fachada oeste de la plaza del Charco, que el Ayuntamiento gestiona en régimen de alquiler. Albergó distintas dependencias municipales, y fue sede de Falange Española (foto 9). Hasta bien entrados los años sesenta sirvió de residencia a tres familias, dos de ellas de funcionarios (un profesor de enseñanza media, un secretario judicial y un chófer de transporte colectivo de viajeros). Asimismo, su planta baja era sede de la carpintería del Ayuntamiento y una importante cerrajería. A lo largo de la década de los sesenta y en los setenta, cuando han sido alojados en viviendas sociales los funcionarios, se transforma progresivamente en una nueva ciudadela, manteniendo como nombre de referencia el de Falange ${ }^{45}$. Su nacimiento no es consecuencia de una medida política programada del Consistorio, sino el resultado de un proceso gradual, en el que los responsables municipales, incapaces de resolver el problema de la vivienda en el municipio, siguen dando este tipo de solución individual a las situaciones concretas que la realidad les va demandando; el resultado es la formación progresiva de una ciudadela cuya función habitacional se mantiene en los ańos setenta. Se trata de una casona canaria del siglo xviII, muy amplia, donde las familias van ocupando distintas dependencias, por lo que es imposible establecer un modelo de habitáculo, adaptándose los residentes a las posibilidades del espacio que se les asigna. Su uso

40 AMPC, acuerdos plenarios, libro 2 (1905-1906), sesión de 19 de marzo de 1906, folio 45.

41 Hernández Castilla, José Melchor, «Las ciudadelas del Puerto de la Cruz, del siglo XX», La Prensa (revista semanal de El Día), 14 de septiembre de 2014, p. 1.

42 Afonso Padrón, Benjamín, «Puerto de la Cruz: Una ciudadela desaparece. Ya hay una asociación de vecinos en Punta Brava», El Día, 4 de noviembre de 1970, Santa Cruz de Tenerife.

${ }^{4}$ Idem.

${ }^{44}$ Hernández Castilla, J.M., op. cit.

45 Se le dio este nombre por haber servido de sede a la Organización de Falange Española hasta los años setenta. Es de titularidad privada, aunque el Ayuntamiento es arrendatario. 


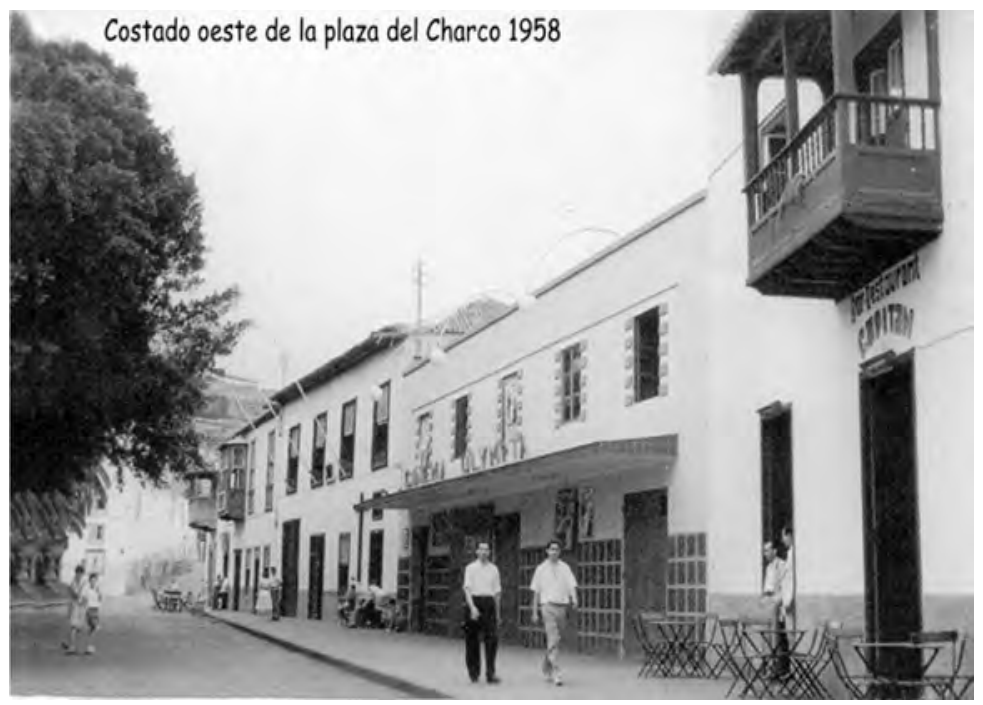

Foto 9. Ciudadela de Falange. Se trata del edificio sin balcones, con mástiles de banderas en la fachada. En 1958 aún era sede de Falange Espańola, de algunas dependencias municipales (carpintería y cerrajería), además de residencia de funcionarios.

como ciudadela concluyó en torno a 1978, cuando sus residentes fueron realojados en el grupo de viviendas sociales de la Cruz del Pino ${ }^{46}$.

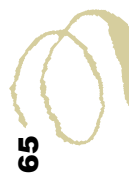

\section{i. Empaquetado de Yeoward}

Como hemos adelantado, esta vivienda colectiva se creó en 1966 para albergar a la población residente en el convento de San Francisco tras su quema ese mismo año. Los afectados fueron realojados en el empaquetado-almacén de plátanos de la empresa Yeoward \& Bross en el desembarcadero de El Penitente, dando lugar al nacimiento de una nueva ciudadela, en cuyo solar se ubica la sede actual del Ayuntamiento portuense. Ciertamente, su existencia resultó muy efímera, puesto que el nuevo edificio municipal fue inaugurado en 1973; es decir, permaneció en uso solo cinco o seis años. Reproduce el modelo seguido en «El Convoy», en una superficie cuadrada, compartimentada con bloques. No disponemos de información alguna acerca de la dotación de servicios higiénicos y sanitarios de los que fue dotada.

46 «Desde el Estado con amor». Op. cit., pp. 17-23. 


\section{CONCLUSIONES}

La vivienda colectiva obrera que se desarrolló en Europa y España desde mediados del siglo xix está presente en el Puerto de la Cruz a lo largo del siglo xx. En este caso, si bien incorpora los elementos esenciales que definen este modelo habitacional, el conjunto de viviendas colectivas analizadas presenta sensibles diferencias respecto de la ciudadela tipo presente en Santa Cruz de Tenerife, Las Palmas, Gijón, etc. (edificio privado, localizado en la periferia urbana, sujetos a alquiler, de una sola planta, etc.).

La vivienda colectiva obrera desarrollada en el Puerto de la Cruz presenta diferencias respecto del modelo de ciudadela más común:

a) En primer lugar, no se trata de edificios construidos específicamente como vivienda colectiva o ciudadela, sino que son resultado del «reaprovechamiento y-en ocasiones- con compartimentación" de edificios o patios destinados a usos diversos que han quedado obsoletos -empaquetados de plátanos, lazareto, central eléctrica de carbón, etc.-, que son reconvertidos y adaptados para transformarlos en residencia de colectivos de clase obrera. A partir de esta constatación, se identifican, al menos, dos tipologías básicas: 1) edificios o construcciones históricas gestionadas por el Ayuntamiento en régimen de propiedad o alquiler; e incluso adquiridos para este fin: convento de San Francisco, casa Cullen, edificio de Falange, etc.); 2) edificios destinados a usos diversos, que han quedado obsoletos o en desuso: empaquetados de plátanos, lazareto, centro de producción de electricidad, etc. cuyas instalaciones son reconvertidas como vivienda colectiva obrera o ciudadelas (El Convoy, Yeoward, El Chavito y El Lazareto). Esta última es una práctica presente en otras ciudades españolas durante los siglos $\mathrm{XIX} \mathrm{y} \mathrm{Xx}^{47}$.

b) Otro aspecto poco común que singulariza las ciudadelas en el Puerto de la Cruz es que, tras la Guerra Civil, la práctica totalidad de las nuevas viviendas obreras que se promueven son de promoción pública; pasando a formar parte de las medidas aplicadas por el Ayuntamiento en materia de vivienda municipal en la etapa franquista; si bien son soluciones de emergencia a desahucios, catástrofes, etc., son constantes y sistemáticas entre 1940-1975, a pesar de su apariencia de improvisación y, en ocasiones, investidas de un carácter de "provisionalidad». En esta línea, la apariencia de solución habitacional «provisional» no se correspondería con las medidas y esfuerzos aplicados en las ciudadelas de El Convoy y convento de San Francisco, adquiridas por el Ayuntamiento para su reaprovechamiento como vivienda colectiva, donde se ejecutaron obras importantes de ampliación y saneamiento, lo cual pone en cuestión o matiza el carácter transitorio de las mismas.

47 Tatjer, M., Op. cit., p. 12. 
Al tiempo, se ha puesto de manifiesto que las ciudadelas del Puerto de la Cruz incorporan los dos elementos esenciales y definitorios de este modelo general:

- Son edificios adscritos a un uso de vivienda colectiva obrera, con un elevado nivel de hacinamiento de sus residentes.

- Las instalaciones sanitarias, de higiene y aseo son de uso colectivo.

Las diferencias o divergencias, sin embargo, son numerosas:

- En primer lugar, en el Puerto de la Cruz se trata de un fenómeno habitacional surgido en el siglo xx; y alcanza su máximo desarrollo en la segunda mitad de la centuria, en pleno desarrollismo y coincidiendo con el boom turístico de la localidad.

- En ningún caso se trata de edificios concebidos y promovidos como vivienda colectiva obrera, sino que son el resultado de adaptaciones, reaprovechamientos o reconversiones de inmuebles diseńados para usos diversos, religiosos, sanitarios, industriales, patios traseros, etc., en algunos casos no habitacionales.

- En el Puerto de la Cruz la mayor parte de las ciudadelas forman parte de la política pública de vivienda de promoción municipal. Son resultado de las medidas aplicadas para resolver el problema municipal de viviendas en la etapa franquista; si bien como soluciones de emergencia improvisadas, en ocasiones con un carácter «provisional». En general, una solución de urgencia y espontánea para paliar la demanda de vivienda para la población trabajadora (la administración pública asume los costes de los desahucios judiciales o administrativos generados por los elevados precios del suelo y el intenso proceso urbanizador de la segunda mitad del siglo Xx).

- Los residentes en las ciudadelas municipales no están obligados a pagar alquiler.

- En la ciudadela del convento de San Francisco se combina la función de vivienda para empleados públicos y vivienda colectiva obrera, si bien separados ambos grupos de residentes.

- Solo las ciudadelas de Mequinez y Los Cubanos son de promoción privada, al tiempo que son las primeras de las que hay noticia, a mediados del siglo $\mathrm{xx}$. En cualquier caso, también son edificios o parcelas reaprovechadas, no viviendas colectivas promovidas y construidas para este fin.

- La disposición geográfica en la periferia del núcleo urbano se cumple en las dos ciudadelas de Mequinez (privadas), El Lazareto, El Chavito. El resto se localiza en el centro de la ciudad, en función de la disponibilidad de inmuebles vacíos de titularidad o gestión municipal potencialmente aptos para la función de vivienda colectiva.

- La centralidad y visibilidad de algunas ciudadelas públicas en el centro urbano, como se ha documentado, actúa como incentivador de los responsables políticos para acelerar y priorizar la construcción de viviendas sociales donde realojar a estas familias. La situación se prolonga hasta finales de los años setenta (1978). Las denuncias públicas en la prensa son numerosas en esos años: Benjamín Afonso, Jesús García Mederos y otros darán cuenta en la 
prensa local, especialmente de las ciudadelas más céntricas (Falange, Cullen o Las Lonjas, y El Convoy, que aún en los setenta están en funcionamiento).

En todo caso, la clausura en 1978 de las últimas «viviendas colectivas obreras» (ciudadelas) en el Puerto de la Cruz no ha supuesto la erradicación definitiva de la infravivienda, o como se quiera llamar. La vivienda es un problema social estructural de este país, que permanece pendiente de una solución satisfactoria y definitiva en el momento actual, de modo que, en los últimos meses de 2018, aún se puede leer en la prensa: «Faltan viviendas asequibles y pervive una legislación contraria a las directivas europeas y a los dictámenes de Naciones Unidas» ${ }^{48}$.

Recibido: 02-03-2019. Aceptado: 11-04-2019

48 Missé, Andeu, «Acabar con la Ley antisocial de Vivienda». El País, 9 de diciembre de 2018. El titular de este artículo ofrece una descripción concisa y clara de la situación de la vivienda en 2018. 


\section{DOCUMENTACIÓN}

AMPC. Actas del Pleno del Ayuntamiento, sesión extraordinaria de 16 de febrero de 1956, libro 578-L (1955-1958), fls. 76 vta., 77 y 77 vta. 1956.

AMPC. Actas del Pleno del Ayuntamiento, sesión extraordinaria de 15 de junio de 1956, libro 578-L (1955-1958), fls. 93 y 93 vta. 1956.

AMPC. Acuerdos plenarios. Sesión plenaria de 21 de agosto de 1953. Libro 577. fol. $161 \mathrm{vt}^{\circ}-162$.

AMPC. Acuerdos plenarios. Sesión plenaria de 27 de septiembre de 1954. Libro 577. fol. 179.

AMPC. Informe Sobre la situación de la Vivienda en el Puerto de la Cruz. Acuerdos plenarios. Sesión plenaria de 2 de septiembre de 1954. Libro 577. fol. 174-177.

AMPC. Relación de viviendas. Signatura 1705. 1950-55.

AMPC. Beneficencia, Sanidad y Calamidades Públicas, Legajo 60, Expediente n. ${ }^{\circ} 14$ (1911-1912). Expediente instruido, en vista de denuncia formulada sobre malas condiciones higiénicas y de salubridad que reúne la casa de "Depósito Municipal», situada en la calle de "Agustín de Bethencourt» (1911-1912).

AMPC. Actas del Pleno del Ayuntamiento, sesión extraordinaria de 2 de agosto de 1954, libro 577-L (1954-1955), fls. 160 y 161. 1954.

AMPC. Actas del Pleno del Ayuntamiento, sesión extraordinaria de 8 de junio de 1954, libro 577-L (1954-1955), fls. 154 vta. 1954.

AMPC. Acuerdos Plenarios. Sesión plenaria de 21 de agosto de 1953. Libro 577. fols. $161 \mathrm{vt}^{\mathrm{o}}-162$.

AMPC. Obras Públicas y Urbanismo, Instancia y Plano presentado por don Dionisio Martín Yumar, Legajo 134. 1928.

\section{Agradecimientos}

José Tomás Real Armas

Agustín Carballo

Rafaela Concepción de Cabo Martín

Manuel Carballo López

Araceli López

Julia Rodríguez

Juan López

Vicente León Real

Juan José González García 
